\title{
A SHARP CONVERSE INEQUALITY OF THREE WEIGHTED ARITHMETIC AND GEOMETRIC MEANS OF POSITIVE DEFINITE OPERATORS
}

\author{
SEJONG Kim, Hosoo LeE AND Yongdo Lim
}

Abstract. In this paper we consider three-weighted arithmetic and geometric means of positive definite operators constructed by the symmetrization method that appeared in the definition of Ando-Li-Mathias's geometric mean of several positive definite operators and we establish a converse inequality of three-weighed arithmetic-geometric means via Specht ratio.

Mathematics subject classification (2000): 47B50, 47A63.

Keywords and phrases: Positive definite matrix, symmetrization method, weighted matrix means, matrix inequality, Specht ratio.

\section{REFERENCES}

[1] M. Alić, P.S. Bullen, J. PeČArić And V. VOLEneC, On the geometric-arithmetic mean inequality for matrices, Math Communication 2 (1997), 125-128.

[2] T. ANDO, C.K. Li AND R. Mathias, Geometic means, Linear Algebra and Appl. 385 (2004), 305-334.

[3] G. CORACH, H. PORTA AND L. RECHT, Convexity of the geodesic distance on spaces of positive operators, Illinois J. Math 38 (1994), 87-94.

[4] S. KIM AND Y. LIM, A converse inequality of higher-order weighted arithmetic and geometric means of positive definite operators, Linear Algebra and Appl. 426 (2007), 490-496.

[5] J. LAWSON AND Y. LIM, Higher order weighted matrix means and related matrix inequalities, submitted.

[6] J. PEČARIĆ, Power matrix means and related inequalities, Math. Commun. 1 (1996), 91-112.

[7] A.C. ThOMPSON, On certain contraction mappings in a partially ordered vector space, Proc. Amer. Math. Soc. 14 (1963), 438-443.

[8] T. YAMAZAKI, An extension of Kantorovich inequality to $n$-operators via the geometric mean by Ando-Li-Mathias, Linear Algebra Appl. 416 (2006), 688-695. 